\title{
Constructional Design Consideration for Long Span flexible Circular grid Roofs
}

\author{
Vaneeta Devi ${ }^{1}$, and A.K.Ahuja ${ }^{2}$ \\ ${ }^{I}$ Assistant Professor, Civil Engg. Deptt., College of Technology G. B. Pant University of Agrill. and Technology \\ Pantnagar, Uttarakhand, INDIA \\ ${ }^{2}$ Professor, Civil Engg. Deptt. IIT Roorkee, Roorkee, Uttarakhand, INDIA
}

\begin{abstract}
The capacity of cable net roofs to cover long spans without intermediate supports and to carry large loads for various types of applications, stimulate the interest of engineer and architects in the sixties. The ability to design large spans with little self weight and high load capacities, as well as exploring new architectural expression, made cable structures very popular, though their structural behaviour is unique and unconventional compared to common structures. The objective of this paper is to describe the typical design consideration for the construction of circular convex cable grid roofs in general achieves efficient and economical design under static loads. Influence of design parameters like cable diameter, cable spacing, rise/sag to span ratio and level of pretension in cables on the performance of cable roof are studied and reported in this paper.
\end{abstract}

Keywords: Cable Roof; Pretension; Flexible Roof; Steel Strand;

\section{Introduction}

Cable supported roof structures have inspired people for many years. With the increase in the demand of suspended cable roof systems, theoretical research work in the field of analysis of them has also increased. Though the analysis of cable structures in guilt complex, evolution of computer and the development of numerical methods for solving large systems of the non-linear equations enable to make detailed study of them. Since the loads are transmitted through tension of the cable, these structures are very stable and efficient. Cable net roofs are used to cover stadiums, swimming pools, exhibition hall, theatres, hanger or even factories. An infinite number of shapes can be produced by pretensioned cable net roofs that depend on the geometry of their boundaries, the curvatures, the levels of cable pre-tensioned and the eventually internal supports. According to cables arrangement style, Cable roofs can be broadly classified as (i) cable-cum- air supported roofs, (ii) cable supported roofs (iii) cable suspended roofs.

In the present study, therefore, it has been planned to investigate the effect of various parameters on the behaviour circular convex cable grid roof (Fig. 1\&2). Parameter to be considered in case of circular convex cable grid roof are level of pretension(P), area of cross-section of cables and struts (A) and rise to span ratio $(\mathrm{h} / \mathrm{L})$ of trusses. Effect of these parameters on maximum deflection, maximum member forces and maximum change in member force are planned to be observed. But due to paucity of sapce, some results of this study are not reported herein. However, conclusion drawn are included it.

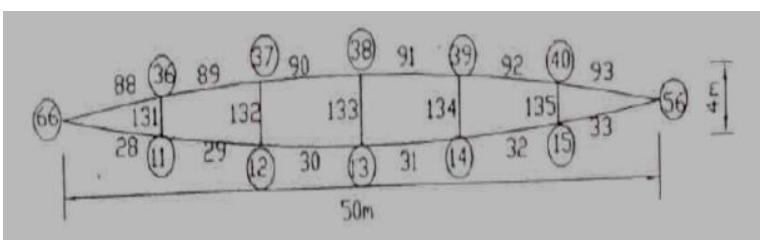

Figure1. Circular Cable Roof

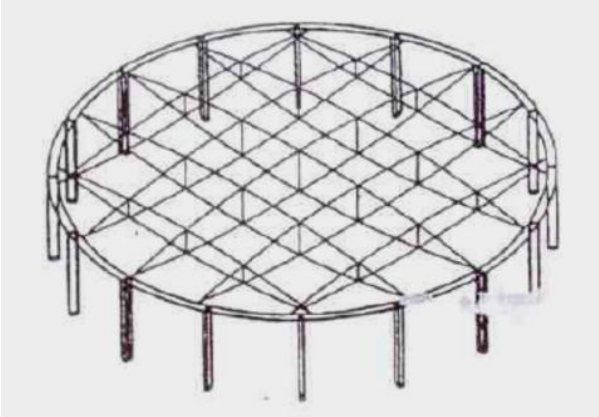

Figure 2. Convex Cable Grid/ Truss 


\section{Details of Circular Convex Cable Grid Roof trusses:}

A Circular Cable Grid Roof with diametre of 50 metre is assumed to be made of parallel convex cable trusses placed in two mutual perpendicular X-directions and $\mathrm{Y}$ - direction (Fig.1). Cables are assumed to be Zinc coated steel structural strand with mudulus of elasticity $(E)=1.66 \times 10^{5} \mathrm{~N} / \mathrm{mm}^{2}$. The area of cables (A) is varied as $387.10,871.0,1548.40,2419.0$ and $3483.90 \mathrm{~mm}^{2}$ w.r.t.diameter of $0.5,1.0,1.5,2.0$, and $2.5 \mathrm{inch}$. The horizontal component of pretension (P) in both sagging and hogging cables of each truss has been varied as 200, 300,400 and $500 \mathrm{kN}$. The cross-section area of cable in trusses has been kept same in both axes i.e. X-directions and Y-direction. The cross-section area strut in trusses is varied as 50,100,150, 200 and $250 \mathrm{~mm}^{2}$.

\subsection{Circular Convex Cable Grid Roof :}

In this case, a convex cable roof is made by placing five numbers of convex trusses in $\mathrm{X}$ and $\mathrm{Y}$ direction at a distance of $8.33 \mathrm{~m}$ over a $50 \mathrm{~m}$ central span of circular roof in plan. This roof has 70 nodes. Out of that 50 nodes are flexible. Node No. 1 to 25 are on the sagging cable whereas 26 to 50 on hogging cabls. It has 145 members. Member no. 1 to 60 on sagging cables whereas 61 to 120 on hogging cables. The vertical member called strut which are to be subjected to compressive force due to pretension are numbered from 121 to 145 . The arrangement of different nodse and members in plan has been shown in fig. 3 \& fig. 4 . A dead load of $30 \mathrm{kN}$ is applied on all flexible nodes of the hogging cables. Cable grid roof has analysed four times by varying crosssectional area of cables and struts but keeping one constant at a time. The oservation has been made for maximum deflection, maximum member force and change maximum member force by varing the structural parametres of convex trusses of circular grid roof. Node number shown thus.

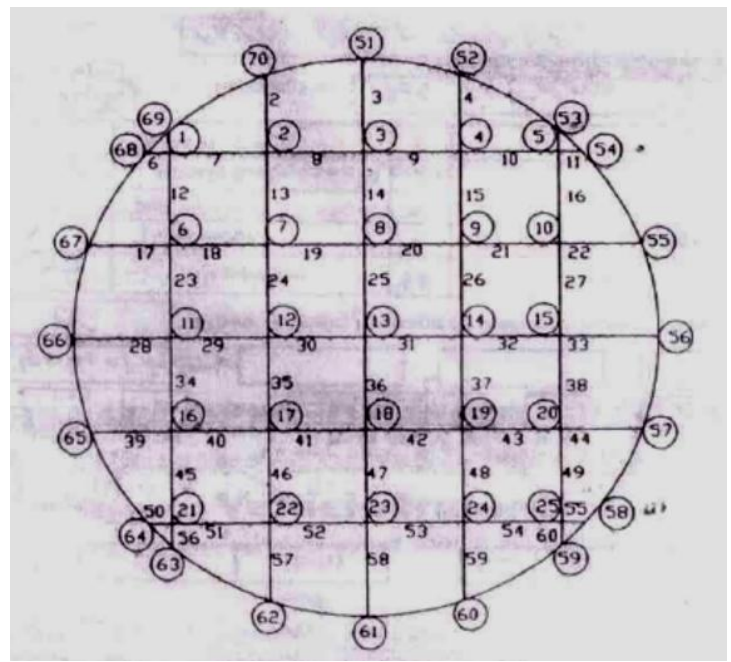

Fig 3: Node no. and member no. on hogging cables

\section{Result and discussion:}

The aim of study is to investigate the influence of certain parameters as mentioned earlier on the behaviour of convex cable grid/ truss roof in general and on maximum deflection, maximum member forces and maximum change in member force in perticular. Non-linear analysis of the roof in carried out using stiffnes matrix method and results obtained are discussed in subsequent articls.

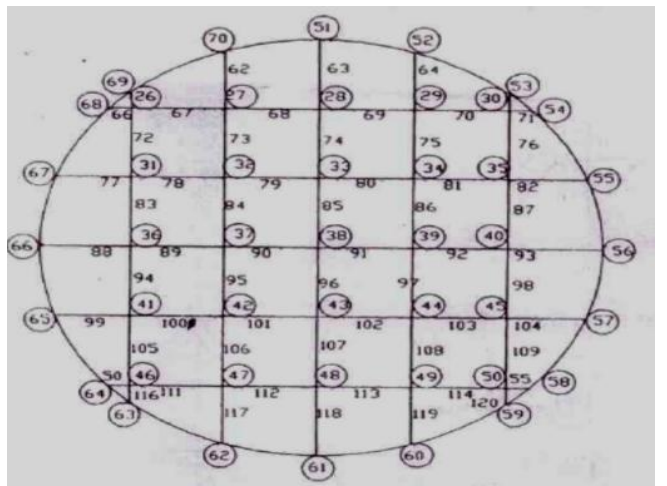

Fig 4: Node no. and member no. on sagging cables 


\subsection{Level of pretension:}

In the present study, pre-tension in both $\mathrm{X}$ and $\mathrm{Y}$ directional sagging and hogging cables has been kept the same. The response of roof is determined for four values of pre-tension namly $200,300,400$ and $500 \mathrm{kN}$ in all the cables. The influence of pre-tension struts on the behaviour of cable truss roof has studied with five numbers of cable trusses and observations has been for maximum deflection, and maximum member forces for all cases are listed in table 1.

Study of values in table 1 indicate that maximum deflection ocured at node no. 40 for pretension force of $200 \mathrm{kN}$. Futher it is seen that while maximum defletion reduces by $18.8 \%$ when pretension in increased by $50 \%$. When pretension is increase by $100 \%$, the reduction in maximum deflection is $15 \%$ only. Influence of pretension $(\mathrm{P} / \mathrm{H})$ value on maximun deflection $(\mathrm{w} / \mathrm{L})$ can be seem in figure 5 , where reference force of pretension $(\mathrm{H})$ is kept $300 \mathrm{kN}$. It is evident from figure that as $(\mathrm{P} / \mathrm{H})$ ratio increases, maximum deflection reduce nonlinearly indicated thereby the non-linear behaviour of circular convex cable grid roof.

Figure 6 shows the plot between various value of force of pre-tension $(\mathrm{P} / \mathrm{H})$ and maximum member force $(\mathrm{F} / \mathrm{H})$. it is observed from the graph that as $\mathrm{P} / \mathrm{H}$ value increses, maximum member force in both sagging and hogging cables increase and show non-linearty is predominate for $\mathrm{P} / \mathrm{H}$ value upto 1.4 only. When horizontal pre-tension force of $200 \mathrm{kN}$ was applied to hogging and sagging cables of the trusses, some of the members becomes slack. However, there was no slacking for $300 \mathrm{kN}$ force of pretension.

\subsection{Area of cross-section of cables:}

Table 1: Effect of Pre-tension on Behaviour of Circular Convex Cable Grid Roof

\begin{tabular}{|c|c|c|c|c|c|c|c|c|}
\hline $\begin{array}{l}\text { Sl.N } \\
\text { o. }\end{array}$ & $\begin{array}{c}\text { Horizontal } \\
\text { pretension } \\
(\mathrm{P}, \mathrm{kN})\end{array}$ & $\begin{array}{l}\text { Node } \\
\text { No. }\end{array}$ & $\begin{array}{c}\text { Maximum } \\
\text { deflection } \\
(\mathrm{w}, \mathrm{mm})\end{array}$ & $\begin{array}{c}\text { Member } \\
\text { number }\end{array}$ & $\begin{array}{c}\text { Maximum } \\
\text { Force } \\
(\mathrm{F}, \mathrm{kN})\end{array}$ & $\mathrm{P} / \mathrm{H}$ & w/L & $\mathrm{F} / \mathrm{H}$ \\
\hline 1 & 200 & 40 & 149.7076 & 3 & 272.9210 & 0.6667 & 0.00299 & 0.9097 \\
\hline 2 & 300 & 28,48 & 121.6290 & 3 & 296.0517 & 1.000 & 0.002433 & 0.9838 \\
\hline 3 & 400 & 28,48 & 104.7120 & 3 & 340.0517 & 1.333 & 0.002094 & 1.1336 \\
\hline 4 & 500 & 28,48 & 93.6130 & 3 & 385.8772 & 1.6667 & 0.001873 & 1.2863 \\
\hline
\end{tabular}

Table 2: Effect of area of cross-section of sagging and hogging cables (A) of the truss on Behaviour of Circular Convex Cable Grid Roof

\begin{tabular}{|c|c|c|c|c|c|c|c|c|}
\hline $\begin{array}{l}\text { Sl.N } \\
\text { o. }\end{array}$ & $\begin{array}{c}\text { cross-section } \\
\text { area of cable } \\
\left(\mathrm{A}, \mathrm{mm}^{2}\right)\end{array}$ & $\begin{array}{l}\text { Node } \\
\text { No. }\end{array}$ & $\begin{array}{c}\text { Maximum } \\
\text { deflection } \\
(\mathrm{w}, \mathrm{mm})\end{array}$ & $\begin{array}{c}\text { Member } \\
\text { number }\end{array}$ & $\begin{array}{l}\text { Maximum } \\
\text { Force } \\
(\mathrm{F}, \mathrm{kN}) \\
\end{array}$ & $\mathrm{AE} / \mathrm{H}$ & $w / L$ & $\mathrm{~F} / \mathrm{H}$ \\
\hline 1 & 387.10 & 38 & 290.865 & 3 & 275.683 & 214.182 & 0.00582 & 0.919 \\
\hline 2 & 871.0 & 28,48 & 157.418 & 3 & 288.949 & 481.924 & 0.00315 & 0.963 \\
\hline 3 & 1548.40 & 28,48 & 121.629 & 3 & 296.053 & 856.729 & 0.00243 & 0.987 \\
\hline 4 & 2419.00 & 40 & 104.472 & 3 & 301.552 & 1338.654 & 0.00208 & 1.005 \\
\hline 5 & 3483.90 & 40 & 94.200 & 3 & 306.591 & 1927.642 & 0.00188 & 1.022 \\
\hline
\end{tabular}

Table 3: Effect of area of cross-section of Hogging cable $\left(A_{h}\right)$ of the truss on Behaviour of Circular Convex Cable Grid Roof

\begin{tabular}{|c|c|c|c|c|c|c|c|c|}
\hline $\begin{array}{c}\text { Sl.N } \\
\text { o. }\end{array}$ & $\begin{array}{c}\text { cross-section } \\
\text { area of cable } \\
\left(\mathrm{A}, \mathrm{mm}^{2}\right)\end{array}$ & $\begin{array}{c}\text { Node } \\
\text { No. }\end{array}$ & $\begin{array}{c}\text { Maximum } \\
\text { deflection } \\
(\mathrm{w}, \mathrm{mm})\end{array}$ & $\begin{array}{c}\text { Member } \\
\text { number }\end{array}$ & $\begin{array}{c}\text { Maximum } \\
\text { Force } \\
(\mathrm{F}, \mathrm{kN})\end{array}$ & $\mathrm{AE} / \mathrm{H}$ & $\mathrm{w} / \mathrm{L}$ & $\mathrm{F} / \mathrm{H}$ \\
\hline 1 & 387.10 & 40 & 130.478 & 3 & 358.6125 & 214.1824 & 0.00260974 & 1.195375 \\
\hline 2 & 871.0 & 28,48 & 124.364 & 3 & 326.2142 & 481.9243 & 0.00248728 & 1.087381 \\
\hline 3 & 1548.40 & 28,48 & 121.629 & 3 & 296.0517 & 856.7293 & 0.00243258 & 1.084429 \\
\hline 4 & 2419.00 & 40 & 121.938 & 3 & 273.5381 & 1338.654 & 0.00243876 & 0.911794 \\
\hline 5 & 3483.90 & 40 & 122.876 & 3 & 273.5039 & 1927.6149 & 0.00245758 & 0.911679 \\
\hline
\end{tabular}

In circular convex cable grid roof, three cases of cross-section area has been carried out. First by varying the cross-section area of both sagging and hogging cables of cable trusses roof in $\mathrm{X}$ and $\mathrm{Y}$ direction. Latter by varying the cross-section area of sagging cables of truss but keeping cross-section area of hogging cables constant. Lastly, cross-section area of hogging cables of truss is varied by keeping cross-section area of sagging cables of truss constant.Horizontal pretension force of $300 \mathrm{kN}$ has applied at the ends of both hogging and sagging cables. The observations for maximum deflection, and maximum member forces for all cases are listed in table $2 \& 3$.

It can be seen from the tables that when cross-section area of both sagging and hogging cables of trusses are increased from $387.10 \mathrm{~mm}^{2}$ to $871.0 \mathrm{~mm}^{2}$ i.e. $125 \%$, maximum defelction in roof reduces from $290.865 \mathrm{~mm}$ to $157.418 \mathrm{~mm}$ i.e. $46 \%$. However, when area of cables are increased from $387.10 \mathrm{~mm}^{2}$ to 1548.40 $\mathrm{mm}^{2}$ i.e. $300 \%$, reduction in maximum defelction in roof 58\%. Figure 7 shows the effect of area of cross-section of cables $(\mathrm{AE} / \mathrm{H})$ and maximum deflection $(\mathrm{w} / \mathrm{L})$. This plot indicates that influence of cable cross-section on maximum deflection of the roof is predominant in the zone of small values of areas of cross- section. It is also 
observed form graph that when cross-section area of both sagging and hogging cables are increased, or only that of sagging cable in increased, maximum deflection decreased sharply for AE/H value up to 1000 and after that it does not show large effect on maximum deflection.

Influence of area of cross-section of cables $(\mathrm{AE} / \mathrm{H})$ on maximun member force $(\mathrm{F} / \mathrm{H})$ can be seem in figure 8 , where reference force of pretension $(\mathrm{H})$ is kept $300 \mathrm{kN}$. It is evident from figure that effect of increase of $\mathrm{AE} / \mathrm{H}$ ratio of both sagging and hogging cables on maximum member force in circular convex cable grid roof is negligible. However, maximum member force increase with increase in cross-section area of sagging cable.

It is also observed that none of the struts member slack with increase of AE/H ratio of both sagging and hogging cables in circular convex cable grid roof. However, some of the member become slack when crosssection area of sagging cable below $1548.40 \mathrm{~mm}^{2}$.

\subsection{Area of cross-section of struts:}

To investigate the effect of variation in cross-section of struts on the behaviour of circular convex grid roof, area of cross-section of struts are taken as 50,100, 150, 200 and $250 \mathrm{~mm}^{2}$ by keeping the pretension force constant as $300 \mathrm{kN}$ and cross-section area of sagging and hogging cables of trusses as $1548.40 \mathrm{~mm}^{2}$ in circular cable grid roof. Maximum deflection, and maximum member forces has been observed .

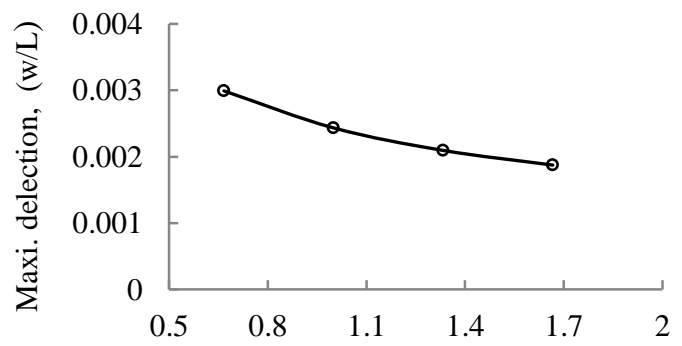

Force of pretension, $(\mathrm{P} / \mathrm{H})$

Fig. 5 Effect of pre-tension of cables on maximum deflection

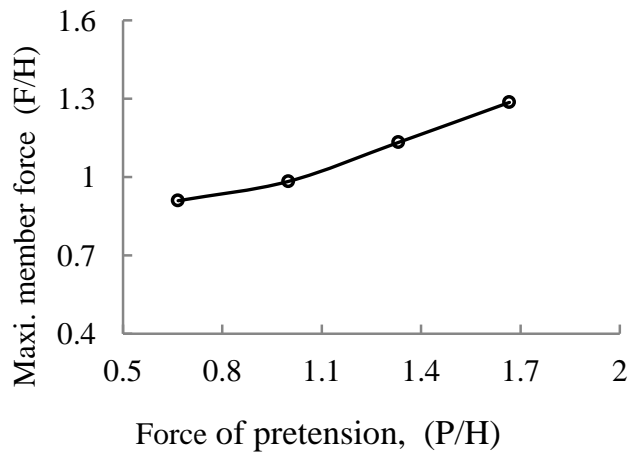

Fig. 6 Effect of pre-tension of cable on maximum member force

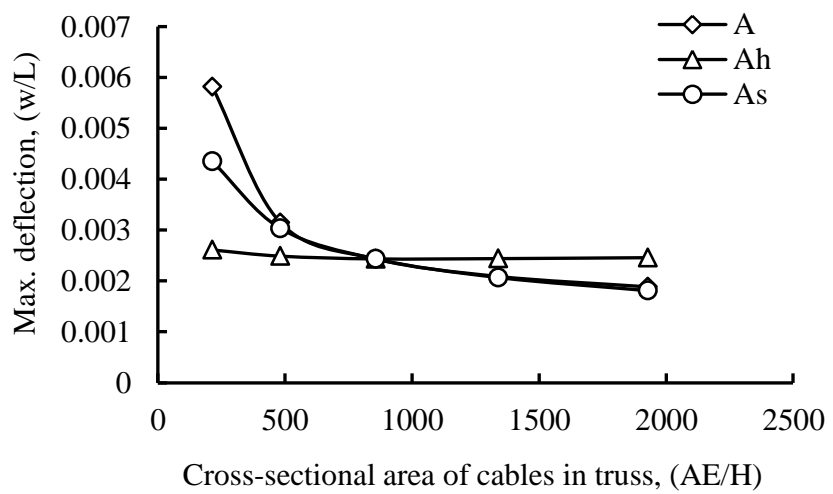

Fig. 7 Effect of cross-sectional area of cables on maximum deflection 


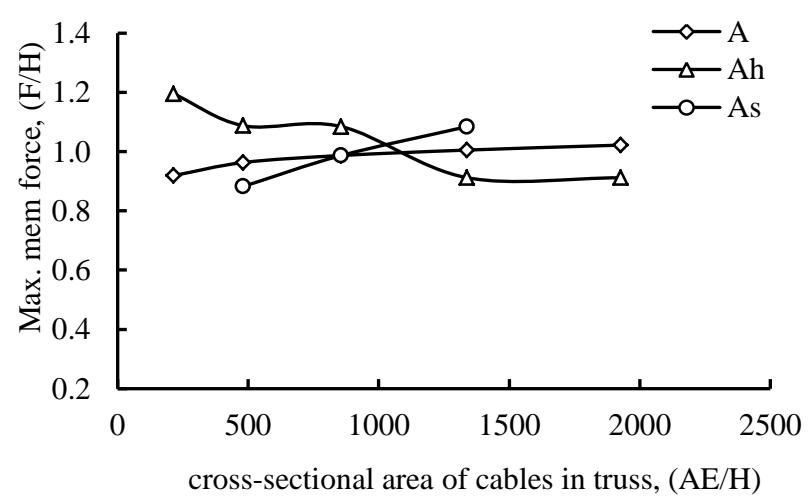

Fig. 8 Effect of cross-sectional area of cable on maximum member force

\section{Conclusion:}

From the study presented in this paper following conclusion are drawn.

1. The behaviour of cable grid roof is influenced by force of pretension applied to sagging and hogging cables of the trusses. As the force of pretension increases, deflections at various nodes decrease. Cable grid roof also shows non-linear bahaviour.

2. Member forces generally increase with force of pretension. However, its effect is more for small values of pretension.

3. The cross-sectional area of hogging cable in trusses does not effect the deflection of grid roofs but maximum deflection decrease with increase in cross-section area of either sagging cable alone or both sagging and hogging cables.

4. Maximum member force is also not affected by variation in cross-sectional area of hogging cables.

5. Increase in cross-sectional area of strut in cable trusses reduces maximum deflection very sharply. Further, the reduction in deflection value is non-linear for small values of area of cross-section of strut.

6. Maximum member force is not much affected by change in cross-sectional area of strut.

7. It is not advisable to increase cross-sectional area of sagging cables beyond a limit, as it will increase dead weight but will not reduce the deflection appreciably.

\section{References:}

[1]. Ahuja, A.K.(1979),"Performance of cable roof systems with rigid and flexible boundaries “. M.E. Thesis, Deptt. Of civil Engg., Univ. of Roorkee ,Roorkee.

[2]. Ahuja, A.K and Garg, V.K (2000), "Parametric study of cable nets".Advances in structural Engineering, Proc. of Second Structural Engg. Convention (SEC-2000), I.I.T.,Bombay, Jan. 5-8, pp. 483-491

[3]. Ahuja, A.K. and Garg, V.K. (2000),"Steel cables for long roofs", Proc. of National Conference on Advances in Construction Materials, Hamirpur (H.P.), April 8-9.

[4]. Ahuja, A.K. and Garg, V.K (1999),"Response of a cable net roofs under static loads". Proc of south -Asian countries Conf. on challenges to Architects and civil Engineers during Twenty-First Century, Nepal Eng. College, Kathmandu, Nepal, April 7-9, pp. 153-165.

[5]. Buchholdt, H.A. (1985), " Introduction to cable roof structures “, Cambridge University Press, London.

[6]. Garg ,V.K. (1997),’Parametric study of hyperbolic paraboloid cable net roofs", M.E. Thesis, Deptt. Of Civil Engg ,Univ . of Roorkee ,Roorkee

[7]. Gupta, V.K. (1971),"Analysis and design of cable roof systems “,M.E Thesis ,Deptt. of Civil Engg, Univ. of Roorkee, Roorkee.

[8]. Jenson, J.J. (1971), "An investigation of static and Dynamic behaviour of suspension structures", Proc. of the IASS Pacific Symposium-Part II on Tension Structures and Space frames, Tokyo and Kyoto

[9]. Krishna, P.(1964), “Analysis of funicular suspension systems”, Ph.D. Thesis, Univ. of London ,London.

[10]. Mittal , A.K.(1978), "A study of comparative performance for different types of cable trusses", M.E. Thesis, Deptt. of Civil Engg.,Univ. of Roorkee ,Roorkee 